\title{
A NARRATIVA AUTOBIOGRÁFICA E A MEMÓRIA DA DITADURA CIVIL-MILITAR: UMA ANÁLISE COMPARADA ENTRE BRASIL E ARGENTINA
}

\section{THE AUTOBIOGRAPHICAL NARRATIVE AND THE MEMORY OF CIVIL-MILITARY DICTATORSHIP: A COMPARATIVE ANALYSIS BETWEEN BRAZIL AND ARGENTINA}

\author{
João Ricardo Pessoa Xavier de SIQUEIRA ${ }^{1}$ \\ Alfredo Adolfo CORDIVIOLA ${ }^{2}$
}

\begin{abstract}
Resumo: Dentre os acontecimentos que contribuíram para a caracterização do século XX como sendo a "era das catástrofes", ou "dos extremos", as ditaduras civis-militares instauradas na segunda metade do século no continente latino-americano podem ser consideradas como fenômenos que reforçam esta ideia. A experiência individual e a vivência coletiva moldadas por esse contexto histórico propiciaram (e ainda propiciam) material considerável para a produção de obras literárias marcadas pela tônica testemunhal, característica aos relatos autobiográficos. Partindo-se desse panorama, o presente trabalho tem como objetivo estabelecer uma análise comparada entre duas narrativas de cunho autobiográfico que se inserem em um escopo mais amplo de obras cujo motivo central é o resgate do passado vivenciado durante os anos de ditadura militar no Brasil e na Argentina. Apresentando a memória - considerada nos planos individual e coletivo - como fio condutor das narrativas, a jornalista brasileira Maria Pilla (2015) e a escritora argentina Nora Strejilevich (2006) fornecem em Volto semana que vem e em Una sola muerte numerosa, relatos autobiográficos de suas vivências enquanto militantes e perseguidas pelos regimes militares que se instauraram nos países mencionados entre as décadas de 60 e 80 . A partir das obras em questão, a abordagem comparada possibilitou a identificação de afinidades na forma como as autoras constituem, processam e materializam a memória do trauma individual e coletivo na tessitura do texto literário.
\end{abstract}

Palavras-chave: Memória. Ditaduras Militares. Relatos autobiográficos. Brasil. Argentina.

\begin{abstract}
Among the events that contributed to the characterization of the twentieth century as the "age of catastrophe", or "age of extremes", civil-military dictatorships established in the second half of the century in the Latin American continent can be considered as phenomena that reinforce this idea. The individual and collective experiences shaped by this historical context have provided considerable material for the production of literary works marked by the testimonial tonic, characteristic of autobiographical narratives. Based on this panorama, the present paper aims to carry out a comparative analysis between two autobiographical narratives that are inserted in a wider scope of works whose central motive is the rescue of the past during the years of military dictatorship in Brazil and Argentina. Presenting the memory - considered at the individual and the collective levels - as the narrative's guiding threads, the Brazilian journalist Maria Pilla (2015) and the Argentinean writer Nora Strejilevich (2006) provide in Volto semana que vem and in Una sola morte numerosa autobiographical narratives of their experiences as militants persecuted by the military regimes that were established in the mentioned countries between the $60 \mathrm{~s}$ and the $80 \mathrm{~s}$. The comparative approach from these works enabled

\footnotetext{
1 Mestre em Relações Internacionais (UEPB). Doutorando em Teoria da Literatura (UFPE). jricardopxsiqueira@hotmail.com

2 Doutor em Estudos Hispânicos e Latino-americanos pela University of Nottingham, Reino Unido (1998). Professor Titular em Teoria da Literatura do Departamento de Letras e do Programa de Pós-graduação em Letras da Universidade Federal de Pernambuco. alfredo.cordiviola@gmail.com
} 
the identification of affinities in the way the authors constitute, process and materialize the memory of individual and collective trauma in the texture of the literary text.

Keywords: Memory. Military Dictatorships. Autobiographical narratives. Brazil. Argentina.

\section{Narrar o trauma e relatar a si: a importância da memória na composição de ficções autobiográficas}

Regimes de exceção por natureza, em que pese o seu caráter notadamente antidemocrático, autoritário e totalitário, as ditaduras militares latino-americanas situam-se como rasgos que maculam o recente e prematuro histórico democrático desses países. Sustentado pelo jugo do militarismo e fomentado pela ideologia cega de uma elite política em prol de uma falsa ideia de desenvolvimento e "ordem", o passado ditatorial latino-americano é permeado por um histórico de repressão e violência responsável pelo surgimento de várias vítimas - dentre as quais estão os milhares de mortos, desaparecidos, torturados, perseguidos e exilados -, além de contribuir para o processo de inscrição do trauma na memória coletiva representado por esse período. A repressão, nesses sistemas, materializava-se em conformidade com uma lógica de cerceamento, docilização e violência perpetrada em face dos corpos políticos (indivíduos ou coletividades) que viessem, sob quaisquer circunstâncias, representar alguma ameaça ou comportamento não compatíveis com as regras segundo as quais deveria funcionar o regime.

Em relação aos modelos repressivos implementados nos países latino-americanos, em especial na Argentina e no Brasil, pode-se afirmar que apresentam entre si aspectos comuns, diferenciando-se de acordo com o que os distingue em suas especificidades. De modo genérico, sustenta-se a ideia de uma lógica sistêmica regulada segundo a dinâmica da Guerra Fria, na qual a contenção do "avanço comunista" constituía-se enquanto imperativo na pauta da política externa norte-americana - daí o apoio e o reconhecimento de tais regimes por parte do governo estadunidense. Além disso, a tomada do poder de assalto pelas Forças Armadas de ambos os países suprimiu direitos e liberdades individuais, resultando em um cenário de repressão e violência de Estado. O legado deixado pelos regimes de exceção aponta não só para aspectos estruturais, a exemplo do atraso econômico e social, mas também para um rastro de terror que se manifesta nos corpos dos sobreviventes e vítimas de tais regimes.

Marcas que se fazem perceber tanto pela inércia institucional do Estado no que compete ao julgamento dos algozes (o Brasil é o único país sul-americano onde os torturadores não 
foram julgados), como por uma espécie de "idolatria" e saudosismo perceptíveis no tom elogioso utilizado por alguns setores da sociedade ao se referirem à ditadura militar. Tais fatores, aliados à ausência do reconhecimento da culpa por parte do Exército, contribuem para que o passado ditatorial permaneça a assombrar e contaminar o presente, como uma ferida mal cicatrizada que se esconde sob uma pele aparentemente saudável.

É, pois, a partir do conhecimento do trauma e da rememoração do medo característicos aos regimes militares que se instauraram no Brasil (1964-1985) e na Argentina (1976-1982) que se constituem as narrativas de Volto semana que vem (2015), de Maria Pilla, e de Una sola mиerte numerosa, de Nora Strejilevich (2006). Os relatos em questão podem ser entendidos como libelos contra o esquecimento dos horrores perpetrados pelos regimes de exceção, na medida em que, empenhados em contestar a narrativa dominante, trazem de volta as vozes dos esquecidos à atualidade. Ambas as autoras assumem ter vivenciado as agruras dos regimes de exceção supramencionados, processando como matéria ficcional suas experiências na construção das narrativas autobiográficas e elaborando uma espécie de reconstrução do trauma a partir do fluxo performativo da memória.

A literatura é nesses casos, portanto, esse lugar de memória ${ }^{3}$ posto ser porta-voz de uma espécie de "memória-dever" dos que sobreviveram (e buscam não esquecer) apoiada em uma "memória-arquivo" - haja vista a necessidade de suportes exteriores, referências tangíveis (e visíveis) - concretizando a vontade de memória (NORA, 1993). Neste ponto, faz-se necessário admitir que um determinado tipo de consciência histórica transcende a noção de conhecimento sobre o passado para adquirir o status de memória, haja vista a sua relação com o conceito de identidade. Afinal, "memória é conhecimento dotado de um índex dotado de identidade, é conhecimento sobre si (...) é a identidade diacrônica própria de alguém, seja como indivíduo ou como membro de uma família, uma geração, uma comunidade, uma nação ou uma tradição cultural e religiosa" (ASSMANN, 2016, p. 112).

O índex de identidade mencionado acima por Jan Assmann associa-se, nas obras elencadas, ao fato de terem as autoras vivenciado o período da ditadura militar de forma direta, o que se deixa perceber no trato com a matéria de memória subjacente às narrativas. Para Éclea Bosi (1994), "por muito que se deva à memória coletiva, é o indivíduo que recorda. Ele é o memorizador e das camadas do passado a que tem acesso pode reter objetos que são para ele, e só para ele, significativos dentro de um tesouro comum" (BOSI, 1994, p. 411). Nas narrativas

\footnotetext{
${ }^{3}$ Para Pierre Nora, "os lugares de memória são, antes de tudo, restos. A forma extrema onde subsiste uma consciência comemorativa numa história que a chama, porque ela a ignora.” (NORA, 1993, p. 12).
} 
em questão, o tempo biográfico e o tempo social interagem a partir do indivíduo que, movido por um desejo de explicação atua sobre o presente e sobre o passado, reconfigurando suas lembranças e integrando suas experiências no fito de dar um sentido a sua biografia (BOSI, 1994).

De maneira complementar a essa compreensão, Judith Butler (2015) identifica uma estrutura tripartite na qual se interpelam o si, o outro e o social na constituição dos relatos de si, a saber:

\footnotetext{
o sujeito sempre faz um relato de si mesmo para o outro, seja inventado, seja existente, e o outro estabelece a cena de interpelação como uma relação ética mais primária do que o esforço reflexivo que o sujeito faz para relatar a si mesmo. (...) os termos usados para darmos um relato de nós mesmos, para nos fazer inteligíveis para nós e para os outros, não são criados por nós: eles têm caráter social e estabelecem normas sociais (BUTLER, 2015, p. 33).
}

Leonor Arfuch (2013), por seu turno, salienta que para além do grau de veracidade da narração, dos propósitos de autenticidade ou de fidelidade da memória, relatar a si tratar-se-á sempre de uma construção na qual a linguagem imprime suas próprias coordenadas de acordo com as convenções do gênero discursivo em questão. "Uma espécie de devir no qual outras vozes falam - inadvertidamente - na própria voz, e que está sujeito às insistências do inconsciente e à intrincada associação de recordações.” (ARFUCH, 2013, p. 81).

Nessa dinâmica, as obras em questão não se encontram na obrigatoriedade de representar o real, mas sim de dar uma forma a ele. Um real que deve ser entendido na chave freudiana do trauma, de um evento que resiste à representação (SELLIGMAN-SILVA, 2003) e que se materializa através de um $e u$ narrador que "empresta um rosto àquele que não o tem, uma máscara que vem ocupar o lugar de uma ausência, que dota de rosto e voz ao que não é previamente um eu. Dito de outra forma: um eu que não é nada além de sua própria representação." (ARFUCH, 2013, p. 82)

Diana Klinger (2008) classifica as escritas de si como um "sintoma" da época atual, na qual muitas obras literárias se voltam para a própria experiência do autor, marcando assim a exaltação do sujeito.

Assistimos hoje a uma proliferação de narrativas vivenciais, ao grande sucesso mercadológico das memórias, das biografias, das autobiografias e dos testemunhos; aos inúmeros registros biográficos na mídia, retratos, perfis, entrevistas, confissões, reality shows; ao surto dos blogs na internet, ao auge de autobiografias intelectuais, de relatos pessoais nas ciências sociais (a chamada antropologia pós-moderna), a exercícios de "ego-história", ao uso dos testemunhos e dos "relatos de vida" na 
investigação social, e à narração autorreferente nas discussões teóricas e epistemológicas (KLINGER, 2008, p. 14).

É interessante pensar as narrativas de Una sola muerte numerosa e de Volto semana que vem, considerando-as como escritas de si a partir da perspectiva proposta por Diana Klinger (2008) que percebe o caráter performático intrínseco às obras dessa natureza. Nas palavras da autora:

A arte da performance supõe uma exposição radical de si mesmo, do sujeito enunciador, assim como do local da enunciação, a exibição dos rituais íntimos, a encenação de situações autobiográficas, a representação das identidades como um trabalho de constante restauração sempre inacabado (KLINGER, 2008, p. 25).

Como condicionantes, o fluxo do tempo, o contexto social, a relação do "eu" que narra (é narrado, ou se faz narrar) com o(s) outro(s) que lhe constituem (o passado em si, o público leitor, ou uma determinada experiência) ditam o ritmo de como se representará o vivenciado e sob qual regime de "verdade" serão julgadas as experiências que se fazem narrar."

O "eu" que narra, passa a ser então agente da escrita e objeto da escritura, diferenciandose da noção de sujeito clássico, como bem pontua Derrida quando afirma: “O sujeito da escritura é um sistema de relações entre as camadas: do bloco mágico, do psíquico, da sociedade e do mundo. No interior dessa cena, é impossível encontrar a simplicidade pontual do sujeito clássico.” (DERRIDA, 2002, p. 222). A clivagem do sujeito encontra vazão no ato autobiográfico entendido como performance na medida em que:

\begin{abstract}
O sujeito que fala ou escreve sobre si, portanto, não é o objeto (re)presentado por seu discurso reflexivo, mas tampouco é o efeito, por assim dizer, gramatical de seu discurso. Falando e escrevendo, literalmente, ele se produz. Narrar-se não é diferente de inventar-se uma vida. Ou debruçar-se sobre sua intimidade não é diferente de inventar-se uma intimidade. $\mathrm{O}$ ato autobiográfico é constitutivo do sujeito e de seu conteúdo (CALLIGARIS, 1998, p. 49).
\end{abstract}

Para Philippe Willemart (2005), a escritura literária se constitui no decorrer das idas e vindas da mente do escritor, por sua mão/corpo, pautada sobre um fio condutor no qual os significantes linguísticos não correspondem (necessariamente) aos significantes do inconsciente. Esse movimento de idas e vindas dialoga, de certo modo, com o expresso por

\footnotetext{
4 "A promessa de dizer a verdade, a distinção entre verdade e mentira constituem a base de todas as relações sociais. Certamente é impossível atingir a verdade, em particular a verdade de uma vida humana, mas o desejo de alcançá-la define um campo discursivo e atos de conhecimento, um certo tipo de relações humanas que nada têm de ilusório." (LEJEUNE, 2008, p. 104).
} 
Michel Foucault (2001) em $O$ que é um autor, quando afirma: "na escritura, não se trata da manifestação ou da exaltação do gesto de escrever, nem da fixação de um sujeito numa linguagem; é uma questão de abertura de um espaço onde o sujeito de escrita não deixa de desaparecer." (FOUCAULT, 2001, p. 270). Em se tratando de textos de natureza autobiográfica mais do que o processo de desaparecimento do autor, o trânsito dos significantes evidencia o encontro do $e u$ textual com o $e u$ narrador, o que consagra o âmbito autobiográfico como espaço dialético entre o eu e o outro (JOZEF, 1998).

No caso específico de relatos de si frutos da experiência com o trauma resultante do passado ditatorial cumpre reportar sobre a persistência da memória que na narração assume uma dimensão não só ética, mas também terapêutica para o sujeito que (se) narra, na medida em que:

diante da dificuldade de transpor para a linguagem vivências dolorosas que estão talvez semiocultas na rotina do cotidiano, no desafio que supõe voltar a dizer, onde a linguagem, com sua capacidade performativa, faz voltar a viver, coloca-se em jogo não somente a forma, mas também o sentido da história pessoal, bem como sua dimensão terapêutica - a necessidade de dizer, a narração como trabalho de duelo. Além disso, a narração assume uma dimensão ética, tendo em vista que restaura o circuito da comunicação - na presença ou na ausência que supõe a escritura - e permite escutar, quase corporalmente, com toda sua carga significante de responsabilidade pelo Outro (ARFUCH, 2013, p. 76).

Faz-se oportuno retomar as contribuições de Freud (2013), haja vista ser patente nas narrativas em análise a presença do luto e da melancolia como vetores que se deixam desencadear por um processo de perda e que reverberam em um esvaziamento do mundo e do ego em si mesmos:

o luto é a reação à perda de uma pessoa querida ou de uma abstração que esteja no lugar dela, como pátria, liberdade, ideal etc. (...) a melancolia se caracteriza por um desânimo profundamente doloroso, uma suspensão do interesse pelo mundo externo, perda da capacidade de amar, inibição de toda atividade e um rebaixamento do sentimento de autoestima, que se expressa em autorrecriminações e autoinsultos, chegando até a expectativa delirante de punição (FREUD, 2013, p. 28).

De maneira geral, pode-se dizer que as obras buscam a problematização de um passado no qual a perda se faz presente no drama das personagens. Seja em seu aspecto mais concreto (a perda de um ente familiar como é no caso de Nora Strejilevich) ou mais abstrato (a perda das 
liberdades individuais que condiciona o medo e aprisiona as personagens em ambas as obras), paira sobre a tessitura narrativa o fantasma da perda. O regime narrativo instaura um clima no qual se faz perceber a perda de algo que poderia ter sido e não foi: perde-se não só um ideal de nação e democracia, mas perdem-se também lugares que não foram ocupados, tempos que não foram vividos, sentimentos que não foram sentidos. Verifica-se então a instauração do lugar do trauma freudiano que aqui busca ser trabalhado pelo exercício da narração.

Tecidas essas breves ponderações teóricas, voltemo-nos à análise das obras na seção seguinte.

\section{Retratos das ditaduras brasileira e argentina na literatura contemporânea: uma tentativa de análise comparada a partir das narrativas de Nora Strejilevich e Maria Pilla}

A abordagem comparada das narrativas de Volto semana que vem e de Una sola muerte numerosa abriga-se na compreensão croceana que consiste em "estudar a obra em todos os seus momentos e antecedentes, nas suas relações com a história política e a história das artes, enfim, a totalidade de seu ser ou da síntese histórico-estética.” (NITRINI, 2015, p. 22). Além disso, o percurso analítico que se pretende seguir insere-se no espectro metodológico da investigação comparatista que elege a tematologia como um eixo possível de análise. Para a pesquisadora Helena Carvalhão Buescu (2001), “através da tematologia os estudos literários abrem-se progressivamente a uma reflexão que encara os fenômenos literários não tanto (ou não apenas) a partir de dados históricos factualmente estabelecidos, mas, sobretudo, a partir dos temas e motivos que os constituem." (BUESCU, 2001, p. 8).

Neste ponto, importa-nos a distinção estabelecida por Trousson (1998) para quem um tema seria a expressão particular de um motivo, a sua individualização. Sendo assim, partindose do pressuposto de que a comparação pode ser utilizada nos estudos literários para indicar afinidades, pode-se apontar que as obras em questão afinam-se nas semelhanças de estilo, estrutura e tônica, tendo em vista que ambas apresentam como motivo a memória da repressão política vivenciada pelas autoras, sendo perpassadas por uma ampla gama de temas, tais como:

o medo, o desaparecimento, a tortura, o exílio, etc. Temas estes particularizados e materializados pelas autoras, que também são personagens em suas próprias narrativas.

Partindo-se da concepção segundo a qual a literatura comparada não se restringe à pura e simples comparação/contraposição entre literaturas nacionais, entende-se que, ao invés disso, “ela fornece um método de ampliação da perspectiva na abordagem das obras literárias, a fim 
de que sejam discernidos movimentos e tendências nas diversas culturas nacionais e de que sejam percebidas as relações entre a literatura e as demais esferas da atividade humana." (ALDRIGE, 1994, p. 255). Por esse ângulo, as obras que servirão como objeto de análise apresentam relações de afinidade temática que se estabelecem em conformidade com a construção de narrativas distintas a partir das memórias em torno de eventos historicamente localizáveis e, na medida do possível, comuns a ambas, quais sejam: as ditaduras militares que se implantaram no Brasil e na Argentina entre as décadas de 60 e 80.

Em Volto semana que vem, publicado em 2015, a jornalista e ex-militante Maria Jacob Pilla reconstitui, a partir de fragmentos, a sua trajetória de revolucionária, perseguida, presa e exilada. O título faz referência à resposta dada pela autora à pergunta feita por seu pai em 1970 quando ele a indagava sobre sua volta após a participação no Congresso da UNE naquele ano. A volta prometida não foi possível, pois a autora teve que fugir para o exílio na França, haja vista a perseguição política em virtude de ser ela vinculada ao Partido Comunista Revolucionário (PCR) e ao Partido Operário Comunista (POC). Chegando na França, Maria Pilla começa a militar junto a IV Internacional, mudando-se posteriormente para a Argentina no intuito de atuar no Partido Revolucionario de los Trabajadores. Em 1975, é presa e torturada pela Polícia Federal Argentina, sendo detida nas prisões de Olmos e Buenos Aires. Em 1978, consegue a expulsão da Argentina e, em sendo considerada perseguida no Brasil, obtém asilo político do governo francês. Retorna ao Brasil só após vinte e dois anos de exílio, em 1992. A obra assume o caráter notadamente de um diário na medida em que a autora busca recompor o seu passado de maneira episódica, recorrendo a micro relatos datados por anos que vão desde a sua adolescência em Porto Alegre e nos Estados Unidos (décadas de 50 e 60) até os dias atuais (alguns episódios datam-se nos primeiros anos do século XXI), passando pelos anos de militância, perseguição, prisão e exílio (décadas de 70 e 80). O modo não linear/não cronológico como se estruturam os episódios na composição da narrativa assemelha-se à imagem da memória enquanto um fluxo caótico e desordenado de lembranças que acometem o sujeito. Embora prevaleça a narração em primeira pessoa, o processo de escrita desvela não só acontecimentos vivenciados pela autora, mas também memórias "inventadas", que lhes foram sendo incorporadas via processos indiretos, acontecimentos que não presenciou diretamente, mas sobre os quais leu ou ouviu.

Em Una sola muerte numerosa, Nora Strejilevich parte de sua própria história enquanto perseguida, sequestrada e sobrevivente da ditadura militar argentina. O relato aparece em 1997, primeiramente nos Estados Unidos, publicado e distribuído em pequena tiragem sob 
responsabilidade da Editora North South Center Press, sendo traduzido para o inglês em 2002. Apenas em 2006, por ocasião do aniversário de 30 anos do golpe militar, e graças às políticas de resgate e preservação da memória, tem-se a publicação na Argentina. A influência das raízes de origem judaica aparece de modo explícito na obra aqui reportada, na medida em que reforçam o componente da memória que transparece na narrativa; nesse caso há a persistência da memória da catástrofe, como se as personagens fossem perseguidas e atormentadas por um trauma duplicado no qual se sobressaem a memória do Holocausto e das ditaduras militares. Sobre memória e judaísmo, Seligmann-Silva (2003) assinala que "a modalidade da memória da catástrofe tem uma longa tradição no judaísmo (...). A religião judaica é, antes de mais nada, estruturada no culto da memória." (SELIGMANN-SILVA, 2003, p. 54). A narrativa, na qual se fundem ficção e realidade, traz em si uma multiplicidade de gêneros literários como o romance, a biografia, a autobiografia e o testemunho e a poesia, ventilando múltiplas vozes, discursos e focos narrativos. A superposição de planos - na qual se intercalam o vivido (a experiência), o discurso oficial e as vozes de outros afetados - funciona como estratégia de modo a se cumprirem os desígnios da reivindicação de uma dimensão subjetiva afeita aos relatos testemunhais (SARLO, 2007). Ao se propor reconstituir a tessitura da vida e a verdade abrigadas na rememoração da experiência, há uma revalorização da primeira pessoa como ponto de vista e a aceitação da memória como campo de conflito na história da Argentina.

Pode-se afirmar que as obras em questão se inserem em um conjunto amplo de narrativas motivadas pelo esforço de ressignificação em torno das memórias dos anos de repressão política pelos quais passaram o Brasil e a Argentina durante o período sob o qual se encontravam sob o jugo do regime militar. Segundo Nelly Richard (2002), parte-se aqui de temporalidade não selada, inconclusa e, portanto, aberta à possibilidade de ser reexplorada em muitas direções. Para a autora, o desafio que encontram tais exercícios estéticos seria o de "funcionar como esteio de elaboração de políticas da memória que lutem contra o esquecimento, no seio de comunidades divididas pelo trauma da violência homicida, e que procuram se reunificar suturando as bordas da ferida que separam o castigo do perdoar." (RICHARD, 2002, p. 53).

No processo de reconfiguração e ressignificação do passado traumático alguns temas são recorrentes nas narrativas das duas autoras, como é o caso do desaparecimento político, ferramenta eficaz para a manutenção do sistema opressor na ditadura argentina. É o desaparecimento de um sem número de indivíduos que move a escrita e intitula a obra de Nora Strejilevich, evidenciando-se a partir da epígrafe que abre a narrativa na qual a citação de Tomás Eloy Martinez, escritor e jornalista argentino, deixa transparecer uma ideia de morte que, 
deixando de ser individual, passa a ser coletiva: "Desde 1975, todo meu país transfigurou-se em uma só morte numerosa que a princípio parecia intolerável e que logo foi aceita com indiferença e até mesmo com esquecimento" ${ }^{2}$. O desaparecimento/sequestro do irmão militante (Gerardo) e da cunhada de Nora Strejilevich funciona como motor da escrita em vários trechos da narrativa, como é o caso do que se destaca a seguir, no qual se percebe a preocupação em traçar um perfil afetivo do modelo de militância e da perseguição que se praticava à época:

Gerardito tem namorada e a traz para dormir em casa. Gerardo escreve panfletos na máquina de escrever de papai. Gerardito é divertido, engenhoso, amigável e audaz. Gerardo escreve muito. (...). Gerardo está fichado. Não vem dormir em casa. Gerardo apoia a violência que vem de baixo e desafia a violência que vem de cima. Gerardo teme porque o seguem. Gerardo insiste. (...) Não se sabe se Gerardo matou ou sequestrou alguém. Sabe-se que sequestram e matam Gerardo (STREJILEVICH, 2006, p. 13, tradução nossa $)^{6}$.

A tática frequente do desaparecimento no modelo de repressão argentino também é referenciada no seguinte excerto de Volto semana que vem, quando da estada de Maria Pilla na prisão de Villa Devoto em Buenos Aires, no qual a fala de um dos oficiais do regime denota a frequência com que se recorria ao chamado "poder desaparecedor":

\begin{abstract}
Ouvimos então um reboliço no fundo do corredor, os guardas se afastavam, soou a voz trovejante do diretor: "Afuera! Afuera!". Galíndez exalava autoridade; não se comovia com nossas vozes de sopranos chorosas. Entrou na cela e, numa ordem medonha mandou que todas saíssemos e o seguíssemos, posicionando-se à frente da fileira dupla de presas. $\mathrm{Na}$ metade do corredor escuro, diante de um policial, mandou aos berros que acendessem as luzes e, cedendo o passo às pressas, fechou com estardalhaço a porta de grades assim que as últimas detidas entraram na grande cela vazia. Ao dar de cara com a parede, o grupo deu meia-volta, deparando-se com o diretor em posição de sentido. "Vocês são duras como o Carvalho, mas eu as envergarei. Aqui não é difícil fazer um preso desaparecer. Têm a ordem, escutem

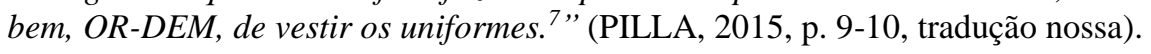

As obras são perpassadas por um tom evidentemente confessional, característico às manifestações da literatura de testemunho, assentado nas experiências pessoais das autoras. Nesse sentido, “a confissão é o ato verbal que torna aparente a verdade, a realidade do que

\footnotetext{
${ }^{5}$ No original: "Desde 1975, todo mi país se transfiguró en una sola muerte numerosa que al principio parecía intolerable y que luego fue aceptada con indiferencia e hasta olvido"

${ }^{6}$ Gerardito tiene novia y la trae a dormir a la casa. Gerardo redacta volantes en la máquina de escribir de papá. Gerardito es divertido, ingenioso, amistoso y audaz. Gerardo escribe demasiado (...) Gerardo está fichado. No viene a dormir a la casa. Gerardo apoya la violencia de abajo e y desafía la violencia de arriba. Gerardo teme porque lo siguen. Gerardo insiste (...). No se sabe se Gerardo mató o secuestró a alguien. Se sabe que a Gerardo lo secuestran y lo matan.

${ }^{7}$ No original: Ustedes son duras como el roble, pero yo las doblegaré. Acá no es difícil hacer un preso desaparecer. Tienen orden, escuchen bien, OR-DEN, de vestir los uniformes.
} 
aconteceu" (BUTLER, 2015, p. 146). Percebe-se que ao narrar, confessando-se e se expondo, as autoras não se colocam em uma posição de críticas de si mesmas, mas se entregam a um modo público de aparição cujo objetivo não é só relatar, mas também denunciar, resgatar e ressignificar o passado vivenciado. O recurso à descrição e o apontamento de fatos e fenômenos históricos contribuem para situar a tessitura narrativa no plano do real, estabelecendo um diálogo necessário com a reescrita de uma história que ainda se encontra em processo. É o caso da menção feita por Nora Strejilevich às Mães e Avós da Praça de Maio, associação de familiares de presos e desaparecidos na ditadura militar argentina que até hoje reivindica a reparação pelos danos causados pelo regime militar na Argentina, conforme se percebe no trecho em destaque:

\begin{abstract}
Agora é a sua vez de viajar sozinha para uma praça com canteiros de flores e um monumento no centro. Toda quinta-feira você se aproxima, entre tímida e desafiadora, para andar no círculo do braço de outra mulher com o mesmo lenço na cabeça, a mesma ausência em uma foto que as faz rodar e rodar. Caminhar e caminhar, e ao caminhar encontrar tantas coisas. Para mim, a praça representa o encontro com nossos filhos. Entrar na rodada é como algo sagrado, como uma cerimônia em que cada membro da família vive à sua maneira. Há um momento em que é preciso ficar em silêncio e não ouvir o que está ao lado: é hora de lembrar (STREJILEVICH, 2006, p. 36-37, tradução nossa) $)^{8}$.
\end{abstract}

Recurso semelhante utiliza Maria Pilla ao descrever a Noite dos Lápis, ocasião em que dez estudantes argentinos foram sequestrados e torturados por ocasião de um protesto ocorrido em Buenos Aires em 1976 pela reivindicação da redução nas tarifas de ônibus.

Na mesma época, pouco depois dos assassinatos, na cidade de La Plata, um batalhão
do serviço de inteligência do Exército e a Polícia da Província de Buenos Aires
sequestraram, torturaram e mataram estudantes do ensino médio, militantes políticos
que faziam campanha pela passagem escolar de ônibus. Três adolescentes
sobreviveram para contar o terror da Noite dos Lápis, como ficou conhecido o
episódio em referência aos estudantes (PILLA, 2015, p. 39).

A partir do vivenciado pelas autoras, concebem-se os espaços narrativos como palcos nos quais se relatam o horror e a violência do real, tendo em vista que "aquele que testemunha, sobreviveu - de modo incompreensível - à morte: ele como que a penetrou" (SELIGMANN-

\footnotetext{
${ }^{8}$ Ahora te toca viajar sola a una plaza con canteros de flores y un monumento en el centro. Todos los jueves te acercás, entre tímida y desafiante, a caminar en círculo de brazo de otra mujer con el mismo pañal en la cabeza, la misma ausencia en una foto que las hace girar y girar. Caminar y caminar, y al caminar encontrar tantas cosas. Para mí la Plaza representa el encuentro con nuestros hijos. Entrar en la ronda es como algo sagrado, como una ceremonia que cada familiar vive a su modo. Hay un momento en que uno necesita estar callado e no escuchar al que está al lado: es el momento de rememorar (STREJILEVICH, 2006, p. 36-37).
} 
SILVA, 2013, p. 52); e a partir da tentativa de narrar o inenarrável, de dizer o indizível, o exercício estético contribui para a apresentação e exposição do passado, de seus fragmentos, ruínas e cicatrizes. É o que se percebe a partir dos trechos destacados a seguir, nos quais as autoras resgatam memórias da época em que foram presas e torturadas:

o cheiro: inesquecível cheiro de roupa suja misturado a um vago odor de pele queimada pelos fios desencapados (PILLA, 2015, p. 46).

Uma vez senti chorar uma pessoa. Veio um a quem chamavam KUNG FU, tirou-a da cela, levou-a a sala de torturas e escutamos os gritos da pessoa enquanto era torturada. Ao trazê-la novamente à cela escutamos que lhe dizia: "não vai chorar mais?" "não senhor" (STREJILEVICH, 2006, p. 31, tradução nossa) ${ }^{9}$.

No que concerne ao plano composicional - materialidade textual da narrativa -, percebese que as autoras se utilizam, em maior ou menor grau, do recurso à intertextualidade para compor as tramas narrativas. Parte-se aqui da noção de intertextualidade elaborada por Julia Kristeva para quem todo texto se constrói como mosaico de citações a partir da transposição de um ou vários sistemas de signos em um outro (apud NITRINI, 2015). As relações intertextuais, sobre as quais se detém a autora, fundamentam-se na noção de dialogismo proposta por Bakhtin que considera "o cruzamento de superfícies textuais como sendo um diálogo entre diversas escrituras: a do escritor, do destinatário (ou do personagem), do contexto atual ou anterior, situando o texto na história e na sociedade.” (NITRINI, 2015, p. 159).

Diante dessa perspectiva, concebendo-se a escritura como subjetividade e comunicabilidade, a diacronia se transforma em sincronia e, à luz dessa transformação, a história linear surge como uma abstração da qual participa o escritor mediante a transgressão, por meio da escritura-leitura na qual história e moral se escrevem e se leem na infraestrutura dos textos (NITRINI, 2015). A noção de sociabilidade subjacente às relações de intertextualidade é ampliada no conceito desenvolvido por Guillén ${ }^{10}$ para quem "o conceito de intertexto leva em consideração a sociabilidade da escritura literária, cuja individualidade se realiza até certo ponto no cruzamento particular e escrituras prévias”. Analogamente a contribuição de Gerard Genette (2006) identifica a intertextualidade como sendo uma "relação

\footnotetext{
${ }^{9}$ Una vez sentí llorar a una persona. Vino un al que le decían KUNG FU, la sacó de la celda, la llevó a la sala de torturas y escuchamos los gritos de la persona mientras era torturada. Al traerla de nuevo a la celda escuchamos que le decía "¿no vas a llorar más?" "no señor (STREJILEVICH, 2006, p. 31).

${ }^{10}$ GUILLÉN apud NITRINI, 2015, p. 165.
} 
de co-presença entre dois ou vários textos, isto é, essencialmente, e o mais frequentemente, como presença efetiva de um texto em um outro." (GENETTE, 2006, p. 8).

Em Una sola muerte numerosa, a intertextualidade faz-se presente a partir dos empréstimos feitos pela autora de trechos de textos extraídos de discursos, pronunciamentos, manchetes de jornais, relatos de experiência, cartas, etc.; esses excertos, geralmente inseridos como epígrafes, entrelaçam-se de modo a construir de maneira coesa e homogênea a trama da narrativa. O leitor é, pois, convidado a seguir a trilha de recortes textuais que compõem a obra, estabelecendo associações, atando nós, preenchendo lacunas e atribuindo-lhes significações. De modo ilustrativo, exemplifica-se com os trechos destacados a seguir, nos quais um trecho da matéria de um jornal e a fala de Garcia Lorca antes de seu fuzilamento introduzem e se conectam, como epígrafes, aos eventos que em seguida serão narrados.

Nos centros clandestinos nos quais atuou, o Turco Julián passeava mostrando um chaveiro com a cruz suástica, tinha uma crueldade especial para com os detentos judeus, levando aos presos literatura nazista para que lessem. La Nación, 2 de maio de 1995

-Vocês são judeus, mas são bons, havia dito à mamãe a vizinha da frente. Eles eram alemães e de acordo com meus país, SS. Refugiados na América do Sul depois da Segunda Guerra Mundial (STREJILEVICH, 2006, p. 25-26, grifo no original, tradução nossa). ${ }^{11}$

- Fogo!

- Não estou morto! Não estou morto!

Federico Garcia Lorca antes do seu fuzilamento

- Vão me matar! Baaastaaa! Estão me matando!

- Gerardo!? É ele. É a voz de Gerardo. Essa certeza me paralisa, me dá vertigem, mas não tenho tempo para não reagir (STREJILEVICH, 2006, p. 31, grifo no original, tradução nossa). ${ }^{12}$

No caso de Volto semana que vem a intertextualidade se faz perceber de modo mais explícito quando da menção ao caso de Rodolfo Walsh, escritor argentino perseguido e morto pelo regime militar. Em episódio/seção intitulada Rodolfo Walsh, um argentino da Patagônia,

\footnotetext{
${ }^{11}$ En los centros clandestinos en los que actuó, el Turco Julián se paseaba mostrando un llavero con la cruz svástica, tenía especial ensañamiento con los detenidos judíos, y los llevaba a los presos literatura nazi para que leyeran. La Nación, 2 de mayo de 1995

- Ustedes son judíos pero son buenos, le había dicho a mamá la vecina de enfrente. Ellos eran alemanes y según mis padres, SS. Refugiados en Sudamérica tras la Segunda Guerra Mundial. (...) (STREJILEVICH, 2006, p. 2526).

12 - ¡Fuego!

- ¡No estoy muerto! ¡No estoy muerto!

Federico García Lorca antes de su fusilamiento

¡Me van a matar! ¡Baaastaaa! ¡Me están matando!

¿Gerardo!? Es él. Es la voz de Gerardo. Esa certeza me paraliza, me da vértigo. No tengo tiempo para no reaccionar. (STREJILEVICH, 2006, p. 31)
} 
Maria Pilla cita diretamente trechos de sua conhecida Carta aberta de um escritor à Junta Militar, escrita em 1977 e que acabou levando, poucas horas depois de trazida a público, ao sequestro e morte do escritor. Levando-se em consideração a relevância do escrito em questão e a articulação do trecho selecionado pela autora que serve não como epígrafe, mas também como elemento que conecta e interage com a narrativa, faz-se oportuno reproduzir o excerto a seguir:

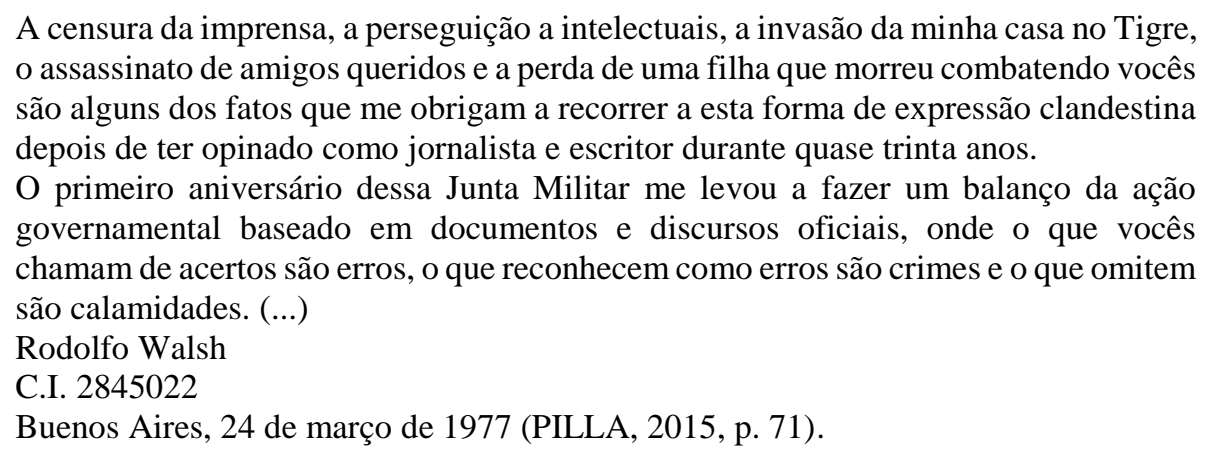

A autora recorre ainda à intertextualidade quando reproduz um trecho do depoimento de Lília Ferreyra, companheira do escritor, fornecido ao jornal El País em 27 de dezembro de 2005. ${ }^{13}$ Ao resgatar a figura de Rodolfo Walsh, Maria Pilla acentua em sua narrativa o caráter traumático que os anos de ditadura representam para a memória coletiva deste país, e ressalta a importância daqueles que sobreviveram para contar sobre as agruras e sofrimento característicos ao período em questão, por meio do resgate de lembranças que, embora aparentemente perdidas, encontram-se em processo de constante reconstrução, conforme se percebe no excerto em destaque abaixo:

Episódios assombrosos perseguiram a memória dos argentinos. Com a ajuda de
sobreviventes, Walsh reconstituiu os acontecimentos tal como ocorreram e não como
foram contados. Escreveu páginas memoráveis da história da sua gente. Sua morte,
no entanto, ainda está cercada de mistério: 1977, o ano em que morreu, já era uma
época sem os sobreviventes que poderiam restabelecer os fatos (PILLA, 2017, p. 72).

Como afirma Linda Hutcheon, “a intertextualidade pós-moderna é uma manifestação formal de um desejo de reduzir a distância entre o passado e o presente do leitor e também de

\footnotetext{
13“'Sobrevivientes que vieron su cuerpo en la Escuela Mecánica de la Armada cuentan que su torso estaba casi cortado en diagonal por la ferocidad de los impactos. Esa noche, el grupo de tareas destruyó la casa de San Vicente y robó todo lo que había en su interior." Trecho do depoimento de Lilia Ferreyra para El País, 27/10/2005 (PILLA, 2015, p. 71-72).
} 
um desejo de reescrever o passado dentro de um novo contexto" (HUTCHEON, 1991, p. 142). É diante dessa dinâmica que se situam as narrativas as quais o presente ensaio propôs-se a analisar, tendo em vista que "cada geração tem a memória de acontecimentos, que nela repercutem restrita ou reiteradamente e que permanecem como pontos de demarcação em sua história" (BOSI, 1994, p. 419). A partir do resgate de lembranças que compõem os seus passados, os sujeitos da escritura das obras então abordadas buscam remodelar o vivenciado em categorias úteis para o presente, empreendendo esforços materializados em um desejo de explicação atuante sobre o presente e o passado, integrando suas experiências como matéria de (re)composição da memória.

\section{Considerações finais}

O presente trabalho buscou esboçar uma tentativa de análise comparada entre duas narrativas ficcionais contemporâneas que têm como motivo central o resgate da memória da repressão política durante os anos em que se instauraram no Brasil e na Argentina regimes de exceção estruturados em torno de governos militares. A vivência na militância, a perseguição política perpetrada pelo sistema repressivo e o trauma inserido nos âmbitos individual e coletivo são temas explorados pelas autoras ao longo do percurso narrativo, no intento de funcionar não só como registro de lembranças individuais, mas também com o intuito de inscrever suas vozes na recomposição de um passado/memória coletiva.

Se é fato que a literatura comparada ocupa-se, dentre outros, com o trato das relações literárias internacionais, cabendo ao comparatista colocar-se nas fronteiras linguísticas, controlando as trocas de temas, ideias, livros ou sentimentos entre duas ou várias literaturas (GUYARD, 1994, p. 96), não se pode ignorar que a memória subjacente aos anos da repressão política perpetrada por governos militares tem fornecido material temático substancial para escritores sul-americanos que situam suas narrativas em torno de vivências pessoais, em um trabalho de constante e perpétua ressignificação que se materializa através da escritura. Identificamos a partir do exame das obras selecionadas nesta análise, traços de afinidade entre a escritura das duas autoras: ambas tem um histórico de militância junto ao passado ditatorial em seus países de origem, ambas sofreram perseguições e viveram na própria pele a perseguição dos regimes de exceção, ambas buscam, a partir de suas memórias, construir suas narrativas partindo da experiência do trauma individual e coletivo. 
Se há afinidades inegáveis entre as duas obras, o que se pode perceber por meio da sua leitura integral e detida, não se podem olvidar, contudo, diferenças sutis que se fazem perceber por meio da manipulação da linguagem e pelo trato com a memória por parte das autoras no que concerne não só ao estilo empregado, mas também em relação ao modo como o trauma se materializa em suas escrituras. Embora ambas as autoras partam da tônica confessional, no que concerne à linguagem empregada por Maria Pilla, percebe-se um estilo que se aproxima mais do matiz utilizado no discurso jornalístico, dando ao leitor a impressão de estar diante de uma entrevista com a própria autora, na medida em que esta resgata os recortes de suas lembranças. Já no caso do estilo empreendido por Nora Strejilevich, percebe-se uma relação mais aproximada à ideia pretensamente "canônica" de linguagem literária, tendo em vista o recurso a uma poética que se instaura por meio de metáforas e imagens que buscam reconstituir, a partir do emprego da palavra, o horror do trauma por ela vivenciado.

A despeito de aproximações ou distanciamentos, fato é que a literatura aqui é fruto de fratura, de cicatrizes ainda expostas advindas de feridas que ainda não se fecharam, resultantes de traumas vivenciados na carne pelas autoras, ou incorporados, direta ou indiretamente, ao processo de formação de suas identidades. Fragmentadas, dialógicas, multifacetadas, as narrativas constroem-se no presente, constituindo-se na provisoriedade de um tempo que não acabou e que dialoga com a necessidade de aproximação do que ainda não foi dito, daquilo que se mantém vivo e pulsante na memória individual e coletiva.

\section{Referências}

ALDRIDGE, A. Owen. Propósito e perspectivas da literatura comparada. In: COUTINHO, Eduardo F.; CARVALHAL, Tânia Franco (orgs.). Literatura comparada: textos fundadores. Rio de Janeiro: Rocco, 1994.

ARFUCH, Leonor. Memoria y autobiografia: exploraciones en los límites. Buenos Aires: Fondo de Cultura Económica, 2013.

ASSMANN, Jan. Memória comunicativa e memória cultural. História Oral. v. 19, n. 1, jan./jun. 2016, pp. 115-127.

BOSI, Éclea. Memória e sociedade: lembranças de velhos. $3^{\text {a }}$ ed. São Paulo: Companhia das Letras, 1994.

BUESCU, Helena Carvalhão. Grande angular: comparatismo e práticas de comparação. Lisboa: Fundação Calouste Gulbekian, 2001. 
BUTLER, Judith. Relatar a si mesmo: crítica da violência ética. Belo Horizonte: Autêntica Editora, 2015.

CALLIGARIS, Contardo. Verdades de autobiografias e diários íntimos. In: Estudos históricos. 1998. n. 21, p. 43-58.

DERRIDA, Jacques. A escritura e a diferença. São Paulo: Perspectiva, 2002.

FOUCAULT, Michel. O que é um autor. In: Ditos e Escritos: estética - literatura e pintura, música e cinema (vol. III). Rio de Janeiro: Forense Universitária, 2001.

FREUD, Sigmund. Luto e melancolia. São Paulo: Cosac Naify, 2013.

GENETTE, Gerard. Palimpsestos: a literatura de segunda mão. Ed. monolíngue. Extratos traduzidos do francês por Luciene Guimarães e Maria Antônia Ramos Coutinho. Belo Horizonte: FALE/UFMG, 2006. (Material em PDF).

GUYARD, Marius-François. Objeto e método da literatura comparada. In: COUTINHO, Eduardo F.; CARVALHAL, Tânia Franco (orgs.). Literatura comparada: textos fundadores. Rio de Janeiro: Rocco, 1994.

HUTCHEON, Linda. Poética do pós-modernismo: história, teoria, ficção. Rio de Janeiro: Imago, 1991.

JOZEF, Bella. (Auto)biografia: os territórios da memória e da história. in: LEENHARDT, Jacques; PESAVENTO, Sandra J. (orgs.) Discurso histórico e narrativa literária. Campinas: Editora da Unicamp, 1998.

KLINGER, Diana. Escrita de si como performance. In: Revista brasileira de literatura comparada, v. 12, 2008.

NITRINI, Sandra. Literatura comparada: história, teoria e crítica. São Paulo: Editora da Universidade de São Paulo, 2015.

NORA, Pierre. Entre Memória e História: a problemática dos lugares. Revista Prof. História. São Paulo: 1993. (10), dez. 1993. p. 7-27.

PILLA, Maria. Volto semana que vem. São Paulo: Cosac Naify, 2015.

RICHARD, Nelly. Intervenções críticas: arte, cultura, gênero e política. Belo Horizonte: Editora UFMG, 2002.

SARLO, Beatriz. Tempo passado: cultura da memória e guinada subjetiva. São Paulo: Companhia das Letras; Belo Horizonte: Editora da UFMG, 2007.

SELIGMANN-SILVA, Márcio. Apresentação da questão da literatura do trauma. In: (org.). História, memória, literatura: o testemunho na era das catástrofes. Campinas: Editora da Unicamp, 2013. 
STREJILEVICH, Nora. Una sola muerte numerosa. Miami: North South Center Press, 1997. Disponível em: <http://norastrejilevich.com/images/USMNTercera.pdf>. Acesso em: 10 jan. 2019.

TROUSSON, Raymond. Temas e Mitos: questões de método. Lisboa: Horizonte Universitário,1988.

WILLEMART, Philippe. Crítica genética e psicanálise. São Paulo: Perspectiva; Brasília: CAPES, 2005.

Recebido em: 08/07/2019

Aprovado em: 07/11//2019 